\title{
Prosthetic Rehabilitation of a Maxillectomy Patient with Post-Surgical Obturator: A Case Report
}

\author{
Meena Kumari Mishra ${ }^{1}$, Raj Kumar Singh ${ }^{1}$, Pramita Suwal ${ }^{1}$, Prakash Kumar Parajuli ${ }^{1}$, Pragya Shrest- \\ ha $^{1}$, Rojina Shakya ${ }^{1}$ \\ Department of Prosthodontics, B. P. Koirala Institute of Health Sciences, Dharan, Nepal
}

\section{Correspondence}

Dr. Meena Kumari Mishra

E-mail: drmeenamishra400@gmail.com

DOI: http://dx.doi.org/10.3126/

jcmsn.v10i4.12976

\begin{abstract}
Case description: A 60 year old female patient presented to Department of Prosthodontics, CODS, BPKIHS, Dharan with a chief complain of loose obturator. History revealed that patient had undergone partial maxillectomy for squamous cell carcinoma 7 years back. The patient also has been wearing obturator which was loose when the patient reported to the department. On examination, the site of surgery was the maxillary right buccal sulcus area and a part of the hard palate including teeth number $11,12,13,14,15,16,17$. The presented defect situation corresponded to a Class I situation (resection performed along the palatalmidline) according to the Aramany classification of defects. The surgical site showed complete healing. A hollow-bulb obturator was fabricated for rehabilitation of the defect. Conclusion: The extensive surgical procedures necessary to eradicate cancer of the head and neck and to prevent local recurrence or regional metastasis often leave extremely large physical defects which present almost insurmountable surgical difficulties in restoring acceptable function or esthetics. The prosthesis rehabilitated the patient in terms of function by providing better masticatory efficiency, phonetics by adding resonance to the voice, hence improving the clarity of speech and also improved the esthetics of the patient.
\end{abstract}

Key Words: Obturator, Partial Maxillectomy, Prosthetic Rehabilitation

Citation: Mishra MK, Singh, RK, Suwal P, et al. Prosthetic rehabilitation of a maxillectomy patient with post-surgical obturator: A case report. JCMS Nepal 2014;10(4):32-6.

\section{INTRODUCTION}

Maxillofacial defects may be a result of congenital malformations, trauma or surgical resection of tumors. The primary objective of rehabilitating these defects is to eliminate the disease and to improve the quality of life for these individuals. ${ }^{1}$ Among various maxillofacial defects, intra oral defects in the form of clefts and opening into the palate are very common. Several methods have been advocated for reconstructing these defects. The use of an obturator prosthesis is one of them. Effective obturation of maxillary defects produces sufficient separation of the oral and nasal cavity to improve the quality and intelligibility of speech. It also enhances masticatory function, deglutition and esthetics. ${ }^{2}$

\section{CASE DESCRIPTION}

A 60 year old female patient presented to Department of Prosthodontics, CODS, BPKIHS, Dharan with a chief complaint of loose obturator. History revealed that patient had undergone partial maxillectomy for squamous cell carcinoma seven years back. The patient also had been wearing obturator which was loose when the patient reported to the department. On examination, the site of surgery was the maxillary right buccal sulcus area and a part of the hard palate including teeth number $11,12,13$, 14, 15, 16, 17 (figure 1). The presented defect 
situation corresponded to a Class I situation (resection performed along the palatalmidline) according to the Aramany classification of defects. The surgical site showed complete healing. A hollow-bulb obturator was fabricated for rehabilitation of the defect.

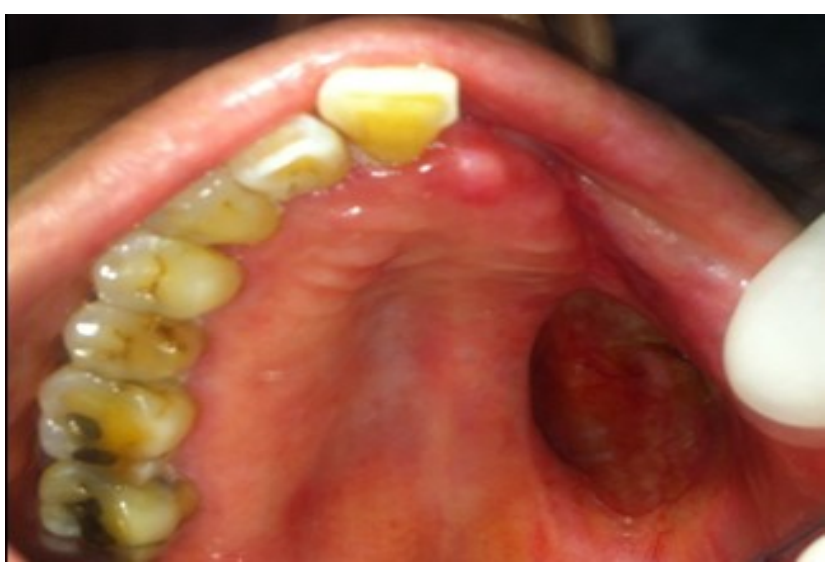

Figure 1: Maxillary Defect

Preliminary impressions were made with irreversible hydrocolloid after blocking the defect undercut with gauze and custom trays were fabricated. Low and high fusing impression compounds were added incrementally to record the extension of the defect area.

The patient was made to perform a variety of movements to shape the impression material according to the associated muscles. At the completion of molding, the roof of the bulb was carefully scraped in its centre to produce a small saucer of $10-12 \mathrm{~mm}$ depth, with borders of the saucer being at least 2-3 $\mathrm{mm}$ wide for collection of secretions, taking care that the borders were not damaged. This would form the future open part of the hollow bulb in its superior half.

This was followed by a routine final impression with zinc oxide eugenol, and the impression was poured out. (Figure 2) The record base and occlusal rim were constructed taking due care not to damage the cast; bite registration records, teeth setting and try in appointment were performed conventionally. (figure 3)

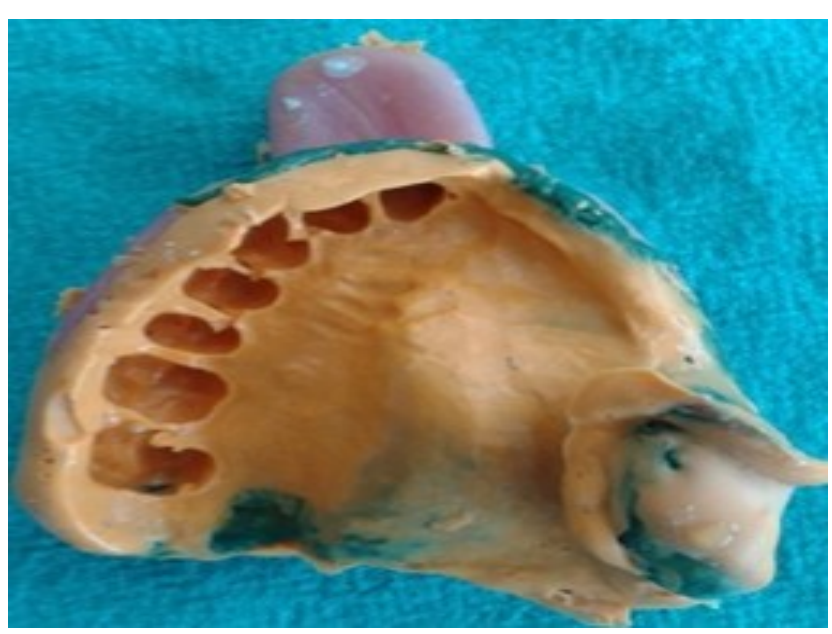

Figure 2: Dual impression of the defect showing a superior open hollow bulb

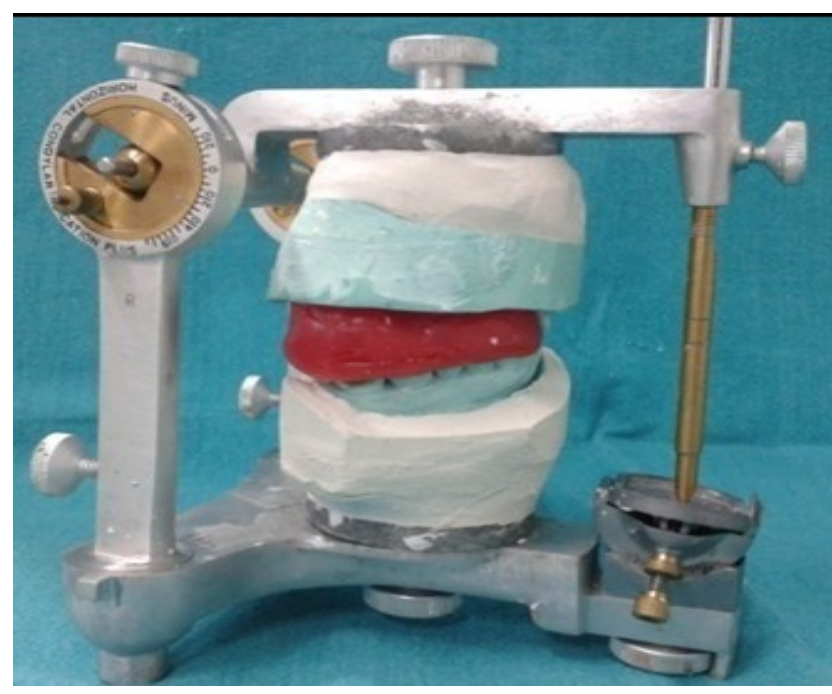

Figure 3: Articulation of occlusal rim after bite registration

After the try in procedure, wax up was done and dentures were made ready for processing. (figure 4) . The maxillary trial denture was flasked (Figure 5) and dewaxed in the conventional manner (Figure 6). Half of the heat cure acrylic resin in dough stage was positioned accurately over the dewaxed mould and then salt crystals were placed over it (Figure 7).

Above that, the remaining heat cure resin was packed and cured for 90 minutes. Cured denture was retrieved and the lid part was removed from maxillary hollow denture to remove the salt crystals. After making sure that all the salt crystals had been removed, the two parts were attached with 
self-cure acrylic resin. (Figure 8) The dentures were inserted in the patient's mouth (Figure 9, 10, 11) and instructions regarding care, hygiene and maintenance were given.
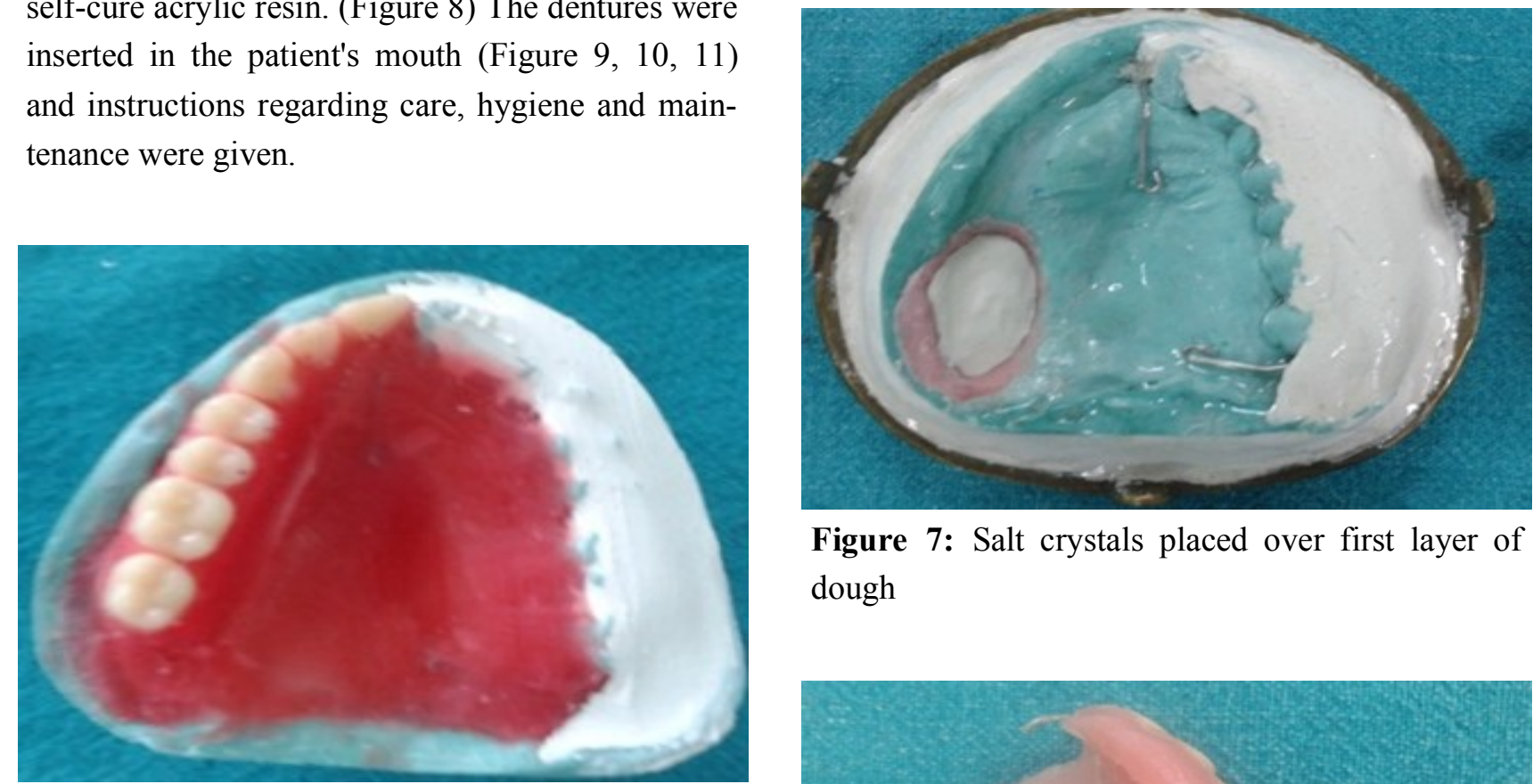

Figure 7: Salt crystals placed over first layer of dough

Figure 4: Waxed up denture
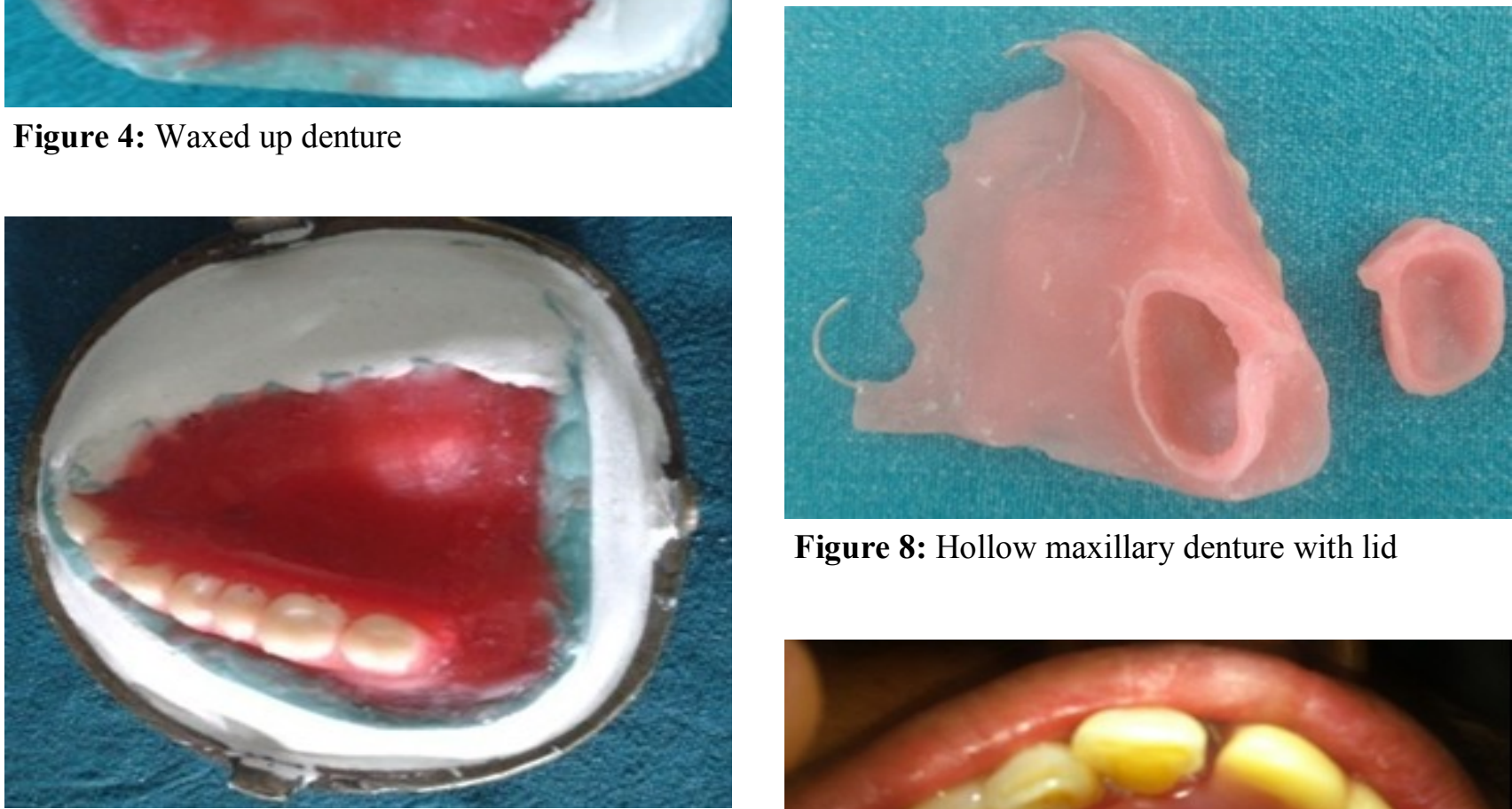

Figure 8: Hollow maxillary denture with lid

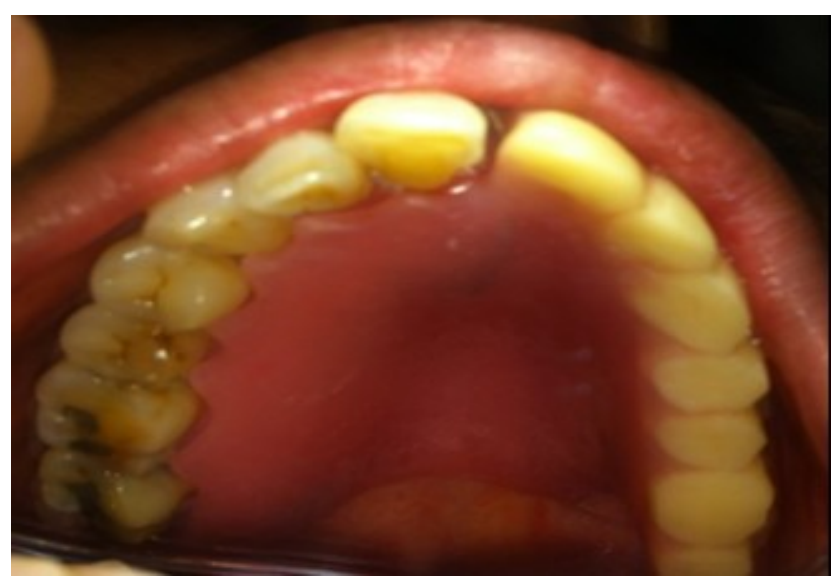

Figure 9: Final prosthesis; occlusal view

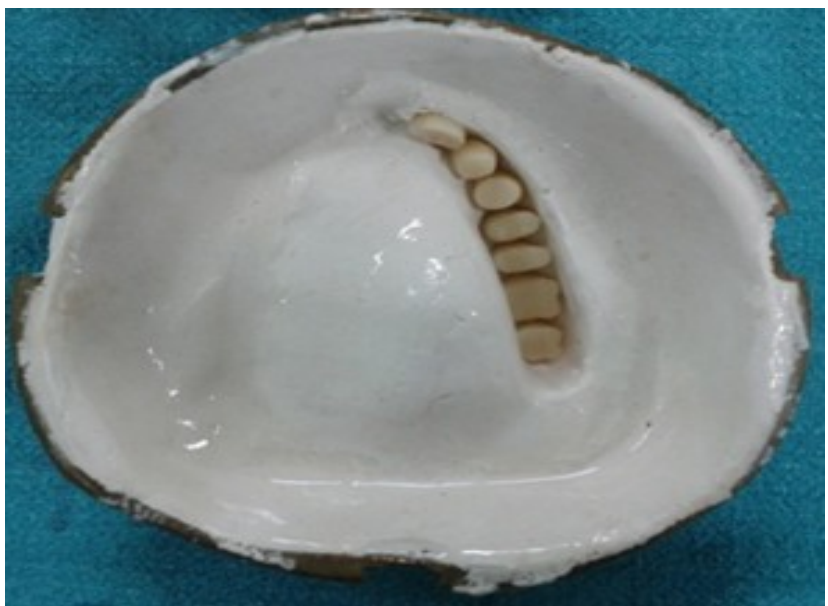

Figure 6: Dewaxing 


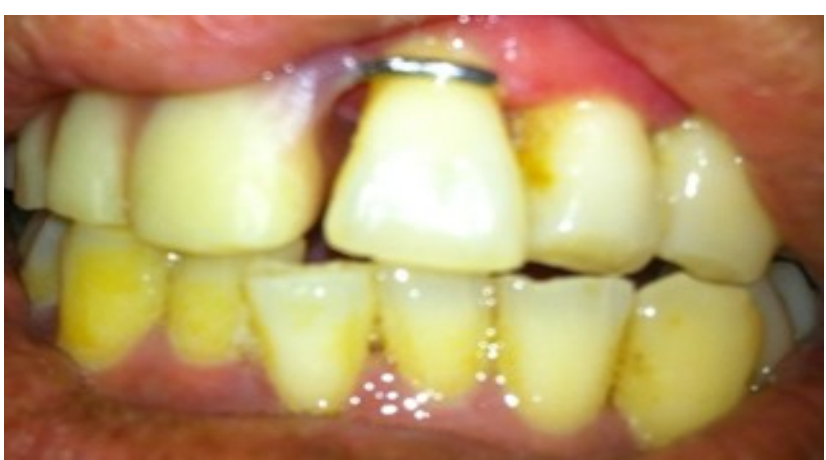

Figure 10: Final prosthesis; frontal view

\section{DISCUSSION}

The method described has advantages over the previously described techniques. The salt crystals being heat labile melt during the curing procedure and thorough flushing after curing results in no crystals remaining in the denture, thereby maintaining the integrity of the denture, avoiding the tedious effort to remove the spacer material from the denture. This technique of lost salt technique is simple to execute and utilizes a very cheap and easily available spacer material.

Extreme resorption of the ridge whether maxilla or mandible will lead to a reduced denture bearing area which in turn will affect retention, stability and support for the complete denture. Problems that are likely to be faced may be due to narrower and more constricted residual ridge as the resorption progresses, causing reduced supporting tissue with larger restorative space between maxillary and mandibular residual ridges. ${ }^{3}$

In general a heavy denture, whether maxillary or mandibular, is likely to cause poor denture bearing ability. Even though it is suggested that gravity and the additional weight to the mandibular complete denture may aid in prosthetic retention, it is not a universally accepted one. Extensive volume of the denture base material in prosthesis provided to patients with large maxillofacial defects or severe residual ridge resorption is always a challenge to a Prosthodontist. In order to increase the retention and stability of heavy prosthesis, many methods have been tried like utilizing the undercuts, modifying the impression technique, use of magnets, use of implants, etc.

Apart from this, when we look into the history of bulkier prosthesis reduction in prosthesis weight also have been tried by making the denture hollow. Such weight reduction approaches have been achieved using a solid three-dimensional spacer including cellophane wrapped asbestos, ${ }^{4}$ silicone putty, ${ }^{5}$ modeling clay, ${ }^{6}$ plaster index, ${ }^{7}$ salt ${ }^{8}$ or thermoplastic splint material ${ }^{9}$ during the laboratory procedures which are removed later to provide a hollow denture base. Parel et $\mathrm{al}^{10}$ and Schneider ${ }^{11}$ have used ice, sugar in the defect portion during processing and later removed by creating holes after processing. Mahdy ${ }^{12}$ used double-flask technique for fabrication of the hollow bulb obturator. But these techniques require more laboratory steps like processing of the obturator bulb and the dentulous area separately. Likewise McAndrewet $\mathrm{al}^{13}$ acquainted an investment method, which requires multiple flasks for fabrication of closed bulb obturator. On the contrary, this procedure had dimensional changes during processing. Tanaka eta $1^{14}$ used polyurethane foam as core material to reduce the weight of the obturator.

The advantages of hollow dentures are reduction in the excessive weight of the acrylic resin, resulting in the lighter prosthesis, and decreased load on the residual alveolar ridges thereby making the patient comfortable.

\section{CONCLUSION}

The extensive surgical procedures necessary to eradicate cancer of the head and neck and to prevent local recurrence or regional metastasis often leave extremely large physical defects which present almost insurmountable surgical difficulties in restoring acceptable function or esthetics. The prosthesis rehabilitated the patient in terms of function by providing better masticatory efficiency, phonetics by adding resonance to the voice hence improving the clarity of speech and also improved the esthetics of the patient. 


\section{REFERENCES}

1. Lethaus B, Lie N, de Beer F, et al. Surgical and prosthetic reconsiderations in patients with maxillectomy. J Oral Rehabil 2010 Feb;37(2):138-42. DOI:10.1111/j.13652842.2009.02031.x.

2. Thota KK, Tella S, Anulekha A, et al. A Prosthodontic Rehabilitation of a Partial Maxillectomy Patient with Hollow Bulb Obturator. Indian Journal of Dental Advancements 2010;2(4):383-6.

3. Bhat A. A hollow complete denture for severely resorbed mandibular ridge. J Indian Prosthodont Soc 2006;6:15761. DOI:10.4103/0972-4052.29369.

4. Nidiffer TJ, Shipman TH. The hollow bulb obturator for acquired palatal openings. J Prosthet Dent 1957;7(1):12634. DOI: 10.1016/0022-3913(57)90016-1.

5. Worley JL, Kneiejski ME. A method for controlling the thickness of hollow obturator prosthesis. J Prosthet Dent 1983;50:227-9. DOI: 10.1016/0022-3913(83)90022-7.

6. Holt RA Jr. A hollow complete lower denture. J Prosthet Dent 1981;45:452-4. DOI:10.1016/0022-3913(81)901128.

7. Minsley GE, Nelson DR, Rothenberger SL. An alternative method for fabrication of a closed hollow obturator. J Prosthet Dent 1986;55:485-90. DOI:10.1016/0022-3913 (86)90183-6.

8. Aggarwal H, Jurel SK, Raghuwar D, et al. Lost salt technique for severely resorbed alveolar ridges: An innovative approach. Contemp Clin Dent 2012 Jul-Sep;3(3):352-5. DOI: 10.4103/0976-237X.103636.

9. Muaiyed M, Buzayan M MClinDent, et al. Closed Hollow Bulb Obturator-One-Step Fabrication: A Clinical Report. J of Prosthodont 2013;Oct;22(7):591-5. DOI: 10.1111/jopr.12036.

10. Parel SM, LaFuente H. Single-visit hollow obturators for edentulous patients. J Prosthet Dent 1978;40:426-9. DOI: 10.1016/0022-3913(78)90126-9.

11. Schneider A. Method of fabricating a hollow obturator. J Prosthet Dent 1978;40:351. DOI: 10.1016/0022-3913(78) 90046-X.

12. El Mahdy AS: Processing a hollow obturator. J Prosthet Dent 1969;22:682-6. DOI: 10.1016/S0022-3913(69)80013 -2 .

13. McAndrew KS, Rothenberger S, Minsley GE An innovative investment method for the fabrication of closed hollow obturator prosthesis. J Prosthet Dent 1998;80:12932.DOI:10.1016/S0022-3913(98)70098-8.

14. Tanaka Y, Gold HO, Pruzansky S. A simplified technique for fabricating a lightweight obturator. J Prosthet Dent 1977;38:638-42. DOI: 10.1016/0022-3913(77)90008-7. 